\title{
Using Polyurethane Foam-Based Passive Air Sampling Technique to Monitor Monosaccharides at a Regional Scale
}

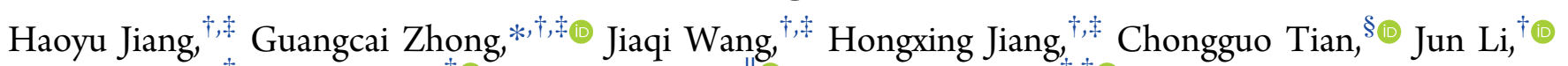

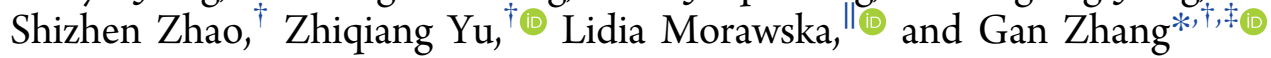

${ }^{\dagger}$ State Key Laboratory of Organic Geochemistry, Guangzhou Institute of Geochemistry, Chinese Academy of Sciences, Guangzhou 510640, P. R. China

${ }^{\ddagger}$ University of Chinese Academy of Sciences, Beijing 100049, P. R. China

${ }^{\S}$ Key Laboratory of Coastal Environmental Processes and Ecological Remediation, Yantai Institute of Coastal Zone Research, Chinese Academy of Sciences, Yantai 264003, P. R. China

"International Laboratory for Air Quality and Health, Institute of Future Environments, Queensland University of Technology, Brisbane, Queensland 4001, Australia

Supporting Information

ABSTRACT: Monosaccharides are important tracers of pollution aerosol from biomass burning. Air sampling of monosaccharides is often conducted using active samplers. However, applicability of sampling monosaccharides using polyurethane foam passive air samplers (PUF-PASs) has not been investigated, since passive air samplers are often applied to monitor semivolatile organic contaminants in large scale and remote area. Our study successfully collected atmospheric monosaccharides using PUF-PASs, providing a valuable tool for monosaccharides sampling. PUF-PAS sampling rates for individual monosaccharides were calibrated using an active sampler for 92 days, and were $1.1,1.5$, and $1.1 \mathrm{~m}^{3} / \mathrm{d}$ for levoglucosan, mannosan, and galactosan, respectively. Degradation of monosaccharides in PUF-PAS was demonstrated to be negligible by spike test of ${ }^{13} \mathrm{C}$-labeled levoglucosan. Furthermore, passive sampling was carried out at 11 sites in the Pearl River Delta of Southern China from January to April and July to September of 2015. Monosaccharide concentrations derived from PUF-PASs were comparable with the reported data obtained by active sampling, demonstrating that the PUF-PAS approach is valid for monosaccharides monitoring. On the basis of our approach, we found that there is a clear correlation between the monosaccharide concentrations and the MODIS fire activities during January-April.

\section{INTRODUCTION}

Biomass burning (BB), particularly open biomass burning events such as land clearing, agricultural waste burning, prescribed burning, field burning, and wildfires, ${ }^{1,2}$ is of global concern for its primary source of pollutant emissions into the atmosphere across the world, and significant impact on air quality and radiation balance of atmosphere. ${ }^{3-5}$ To track contribution of $\mathrm{BB}$ to atmospheric pollutants relative to other sources, molecular markers can be used. Levoglucosan, together with its isomers mannosan and galactosan, have been widely used as molecular markers of emissions from $\mathrm{BB},{ }^{6}$ due to advantages such as large quantities emitted, and little interference from other sources. ${ }^{7-9}$ The monosaccharides are degradation products of cellulose, occurring as specific indicators of $\mathrm{BB}^{7}$

Atmospheric levoglucosan sampling was commonly carried out by active air samplers (AAS) ${ }^{10-12}$ Most studies focused on levoglucosan in particle phase collected by AAS, while the gas phase was overlooked. ${ }^{13-15}$ However, levoglucosan was supposed to be a semivolatile organic compound (SVOC), ${ }^{13,16,17}$ partitioning of which in gas phase could be significant under specific environmental conditions. ${ }^{13}$ Laboratory studies reported a vapor pressure of $\sim 2.0 \times 10^{-4} \mathrm{~Pa}$ and an estimated octanol-air partitioning coefficient $\left(K_{\mathrm{OA}}\right)$ of $\sim 1$ $\times 10^{10}$ of this compound at $298 \mathrm{~K}^{13,14,18}$ May et al. (2012) reported that at least $10 \%$ appreciable gas quantities of levoglucosan were found under typical atmospheric conditions (with organic aerosol (OA) concentration of $C_{\mathrm{OA}}=5 \mu \mathrm{g} / \mathrm{m}^{3}$ and temperature of $298 \mathrm{~K})$. Model results even showed that almost $95 \%$ of levoglucosan existed in the gas phase during wildfires in the summertime, while the value decreased to less than $10 \%$ during wood burning in colder winter temperature. ${ }^{13}$ Recently, a field study on gas/particle partitioning of

Received: April 27, 2018

Revised: September 21, 2018

Accepted: September 23, 2018

Published: September 24, 2018 
levoglucosan at an urban site using AAS observed that gasphase concentrations were $0.02-3$ times comparing with the ones in the particle phase during the sampling period. ${ }^{15}$

In the last two decades, passive air samplers (PAS) were widely used in the sampling of SVOCs, such as PCBs, PBDEs, and PAHs. ${ }^{19-24}$ Due to the facts including the small size, the low cost, the portability, the easy installation, the power-free operation and the convenient maintenance of PAS, it is more applicable for a large-scale and a long-period sampling comparing with active samplers. ${ }^{25,26}$ However, as for its application in a sampling of levoglucosan in air, to our knowledge, has not been reported. Polyurethane foam (PUF) disk based on PAS (PUF-PAS) is the most popular PAS type. ${ }^{22,27-30}$ PUF-PAS was originally used to collect gas-phase compounds, but there was an application in both gas and particle phase, or solely particle phase samplings nowadays. ${ }^{31}$ Good agreement has been found between the concentrations and size distributions for the particles less than $2.5 \mu \mathrm{m}$ measured inside and outside of several popular PUF-PAS designs. ${ }^{32}$ Thus, not only gas-phase chemicals but also particles less than $2 \mu \mathrm{m}$ typically represented by $0.3-0.5 \mu \mathrm{m}$ can be sampled by a PUF disk because of the similar aerodynamic behavior to gases. ${ }^{25,26,33}$ Since the diameter of ambient particle-phase levoglucosan is smaller than $0.44 \mu \mathrm{m}$ when $\mathrm{BB}$ tracers originate directly from the source emissions, while typically ranging from 0.44 to $1.0 \mu \mathrm{m}$ when it is aged and sampled away from combustion sources. ${ }^{34,35}$ It is also reported that the concentrations of levoglucosan in $\mathrm{PM}_{1}$ and $\mathrm{PM}_{2.5}$ were comparable, either of them accounting for at least $50 \%$ of $\mathrm{PM}_{10}$ in the PRD region. ${ }^{36}$ Therefore, the application of PUF-PAS should be feasible for collecting both gas- and particle-phase monosaccharides.

Sampling rates of PUF-PAS are influenced by physicochemical properties of target compounds, superficial area and volume of PUF, design of sampler, atmospheric conditions ${ }^{13,37}$ (e.g., photooxidation conditions, ambient temperature, background OA concentration, and etc.) and meteorological parameters $^{26,38,39}$ (e.g., wind speed, temperature, humidity, aerosol concentration, and so forth $).^{40}$ Sampling rates could be varied in the range of $0.7-8 \mathrm{~m}^{3} / \mathrm{d}$ for particle associated SVOCs, such as polycyclic aromatic hydrocarbons (PAHs).

In the present work, we determined the sampling rates of levoglucosan and its isomers using a PUF-PAS consisting of a double-dome sampling chamber. PUF-PAS in the same design has been used in previous studies on persistent organic pollutants (POPs). Sampling rates of PUF-PAS were calibrated by a codeployed AAS for 92 days. Degradation of levoglucosan during passive sampling was monitored by spiking of ${ }^{13} \mathrm{C}_{6}$ levoglucosan. Finally, two campaigns of passive sampling were carried out to monitor monosaccharides in the air of the Pearl River Delta (PRD) region in China. Levoglucosan levels derived by PUF-PAS were compared with literature AAS results from the same region, as well as regional satellite fire counts results.

\section{MATERIALS AND METHODS}

2.1. Calibration Exercise for Monosaccharides. Passive samplers used in this study consisted of a PUF disc $(14.0 \mathrm{~cm}$ diameter, $1.35 \mathrm{~cm}$ thickness, $365 \mathrm{~cm}^{2}$ surface area, $3.40 \mathrm{~g}$ mass, $207 \mathrm{~cm}^{3}$ volume, and $0.0213 \mathrm{~g} / \mathrm{cm}^{3}$ density), ${ }^{41}$ which was housed in two stainless steel domed chambers to dampen the effect of wind speed on the uptake rate and to protect the PUF disks from precipitation, direct particle deposition, and ultraviolet radiation. ${ }^{25,27}$ More detailed information on the sampler was shown in Table S1 of the Supporting Information (SI). The PUF disks were precleaned by extraction with a mixture of methanol and dichloromethane (DCM) $(7: 93, v / v)$ for $36 \mathrm{~h}$. Chambers were precleaned and solvent-rinsed with methanol beforehand. A total of 15 passive samplers were set up and deployed from the $26^{\text {th }}$ of July to the $26^{\text {th }}$ of October in 2016 for over a 92-d period. The sampling site was on the roof of an office building $(\sim 30 \mathrm{~m})$ at the Guangzhou Institute of Geochemistry, located at an urban site in Guangzhou, China, without any obvious point emission sources nearby. During the calibration exercise, the daily temperature ranged from $25^{\circ} \mathrm{C}$ to $31{ }^{\circ} \mathrm{C}$, with an average of $29 \pm 1.6^{\circ} \mathrm{C}$. The daily relative humidity (RH) ranged from $61 \%$ to $85 \%$, with an average of 73 $\pm 6.8 \%$. Other information on basic environmental and meteorological parameters during the calibration exercise is shown in Table S2. PUF-PASs were hung approximately 1.5 $\mathrm{m}$ above the ground in an open area. All the PUF disks were pretreated with $14 \mu \mathrm{g}$ of ${ }^{13} \mathrm{C}_{6}$ levoglucosan as a degradation reference prior to deployment. Every three parallel PUF disks were collected at 16, 30, 50, 73, and $92 \mathrm{~d}$ intervals over the period (Table S3). In the meantime, active air sampling was conducted continuously alongside the passive sampling throughout the calibration exercise. The AAS was set at an identical height for the deployment of the passive sampler. A total of 16 pairs of total suspended particle (TSP) samples were collected on prebaked $\left(450{ }^{\circ} \mathrm{C}, 4-5 \mathrm{~h}\right.$, muffle furnace) quartz fiber filters (QFFs, $18 \times 10.5 \mathrm{~cm}^{2}$ ), and gas samples were collected by the PUF plugs. The samples were collected for a 3-7 day duration at a stable flow rate of $300 \mathrm{~L} / \mathrm{min}$ (Table S3). After sampling, all folded QFFs, PUF plugs, and PUF disks were wrapped in aluminum foil, sealed in PE bags, and stored in a refrigerator at $-20{ }^{\circ} \mathrm{C}$ before analysis. It should be noted that because of the unavoidable factors including the interruption of a power supply, the super heavy rainfall, and the typhoon, the active sampling time did not fully match the retrieve time of PUF-PAS (Table S3). For example, the passive sampling duration of the first period was from the $26^{\text {th }}$ of July to the $11^{\text {th }}$ of August, its corresponding active samples were Number 1-3. In this case, the average concentrations of monosaccharides derived by active sampling during the corresponding deployment time of PUF-PAS were used as the referenced air concentrations during the calibration exercise.

2.2. Field Sampling in the PRD. Eleven locations belonging to the environmental monitoring network of Guangdong Provincial Environmental Monitoring Center were selected with the intention of avoiding point sources contamination. It includes 5 urban sites (ZQ (Zhaoqing), TH (Tianhe), FS (Foshan), ZH (Zhuhai), and SZ (Shenzhen)), 5 rural or suburban sites ( $\mathrm{CH}$ (Conghua), JL(Jiulong), JM (Jiangmen), JGW (Jinguowan), and BL (Boluo)), and 1 background site (TJ (Tianjin Mountain)) (Figure 1). Details of each sampling site and basic related parameters are given in Tables S4 and S5. Samplers were assembled at the deployment sites to avoid contamination during transit. PUF-PASs were deployed for approximately 58 days in Jan-Apr (January 30 to April 15) and 66 days in Jul-Sep (July 6 to September 16) of 2015. After deployment, the PUF disks were retrieved, resealed, and returned to Guangzhou, where they were stored and kept frozen until extraction and analysis.

2.3. Monosaccharides Analysis. Monosaccharides collected on QFFs and PUF disks were analyzed by validated 


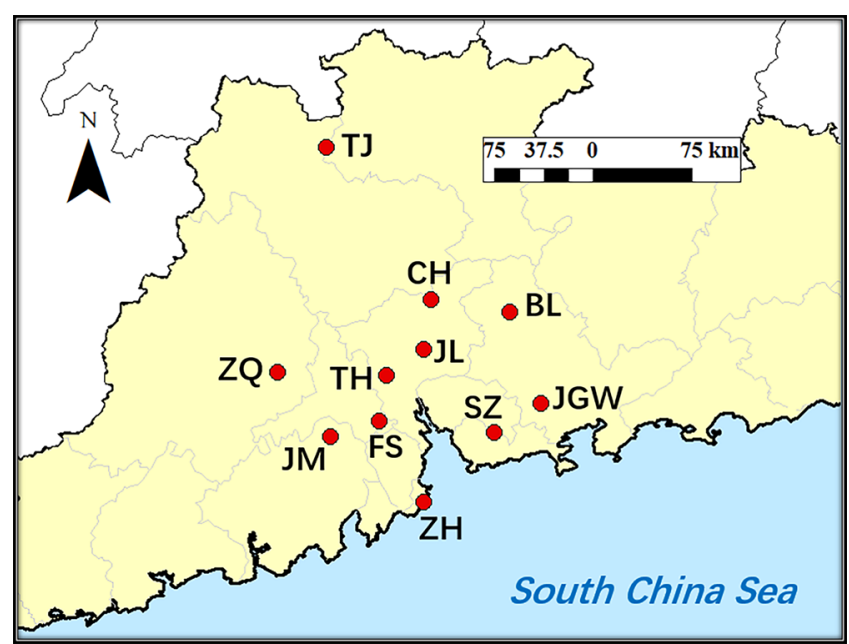

Figure 1. Map of the sampling sites.

methods with details provided in Section S1 of the SI. Briefly, the aliquots for the QFFs, PUF plugs, and PUF disk samples were spiked with methyl- $\beta$-D-xylopyranoside (MXP) or ${ }^{13} \mathrm{C}_{6}$ levoglucosan as internal standards. Samplers were then Soxhlet extracted for $36 \mathrm{~h}$, concentrated with a rotary evaporator and pure nitrogen gas and derivatized by $\mathrm{N}$, O-bis (trimethylsilyl) trifluoroacetamide (BSTFA) with $1 \%$ of trimethylsilyl chloride and pyridine $(2: 1, \mathrm{v} / \mathrm{v})$ at $70{ }^{\circ} \mathrm{C}$ for $1 \mathrm{~h}$. The derivatives were dried by nitrogen and diluted by the addition of $n$-hexane prior to the quantification by gas chromatography-mass spectrometry (GC-MS).

2.4. QA/QC. A total of 2 sets of field blanks consisted of QFFs, PUF disks, and plugs for the calibration exercise, 2 field blanks of PUF disks for the PRD sampling campaigns, and 7 procedural blanks were extracted and analyzed in the same manner as the samples. The analytes in the laboratory and the field blanks were significantly lower than the concentration of the field samples. For the field blanks, only small amounts of monosaccharides were detected in PUF plug and PUF disk, with average values lower than 220,10 , and $28 \mathrm{ng} /$ sample for levoglucosan, mannosan, and galactosan, respectively, which were typically less than $5 \%$ of sample amounts. Field blank data have been subtracted from all the samples.

To evaluate recoveries during pretreatment procedures, ${ }^{13} \mathrm{C}_{6}$ levoglucosan was spiked in the blank samples as a surrogate, then $1000 \mathrm{ng}$ of MXP and hexamethylbenzene (HMB) were added as quantification internal standards before derivatization and before injection, respectively. The recovery of ${ }^{13} \mathrm{C}_{6}$ levoglucosan ranged from $85 \%$ to $150 \%$ for PUF disks when using $\mathrm{HMB}$ as the internal standard. When taking the derivatization efficiency into consideration, the recovery ranged from $95 \%$ to $110 \%$ for QFFs and from $52 \%$ to $130 \%$ for PUF plugs and disks when using MXP as the internal standard. The method detection limit (MDL) was defined as the average of the blanks plus 3 times the standard deviation, which was 97, 22, and $5.7 \mathrm{ng} /$ sample for levoglucosan, mannosan, and galactosan, respectively. All the reported results were corrected with surrogate recoveries.

In this study, all the meteorological parameters were obtained from the Web site of https://www.aqistudy.cn/. Terra MODIS statistics of thermal anomalies/daily fire products (MOD14A1) were downloaded from https:// ladsweb.modaps.eosdis.nasa.gov/api/v1/productPage/ product=MOD14A1.

\section{RESULTS AND DISCUSSION}

3.1. Feasibility of Using PUF-PAS to Determine Air Concentrations of Monosaccharides. 3.1.1. ParticlePhase Fraction of Monosaccharides in the AAS Samples. All the data for the monosaccharides concentrations, including the gas- and the particle-phase concentrations, are summarized in Figure S3, Table S6 and Section 2 of the SI. The particlephase fraction parameter, $\phi_{\mathrm{p}}$ :

$$
\phi_{\mathrm{P}}=\frac{C_{\mathrm{P}}}{C_{\mathrm{P}}+C_{\mathrm{G}}}
$$

has often been used to describe the partitioning behavior of SVOCs in air, where $C_{\mathrm{p}}\left(\mathrm{ng} / \mathrm{m}^{3}\right)$ and $C_{\mathrm{G}}\left(\mathrm{ng} / \mathrm{m}^{3}\right)$ are the particle- and gas-phase concentrations of the target compound, respectively. The $\phi_{\mathrm{p}}$ for levoglucosan varied from $41 \%(\mathrm{RH}=$ $70 \%)$ to $97 \%(\mathrm{RH}=70 \%)$, with an average value of $78 \pm 18 \%$ (Table S7 and Figure S4). The $\phi_{\mathrm{p}}$ for mannosan and galactosan were in the range of $9.3-92 \%$ and $17-78 \%$, with average values of $59 \pm 27 \%$ and $52 \pm 18 \%$, respectively. The ratios of gas- to particle-phase $\left(C_{\mathrm{G}} / C_{\mathrm{p}}\right)$ of levoglucosan ranged from 0.03 to 1.44 , with the median value of 0.17 (Table S7), which were comparable to those reported in the previous study (0.02-3.04, 0.23 (median value)) conducted in Denver, Colorado (U.S.A.), showing that the semivolatile characteristics of levoglucosan and reporting the non-negligible impact of gas-phase levoglucosan on the total concentration. ${ }^{15}$

Although the significantly high concentrations of primary organic aerosol (POA) (hundreds of $\mu \mathrm{g} \mathrm{m}^{-3}$ ) favors the particle phase, particle-phase concentrations from $\mathrm{BB}$ sources will be rapidly diluted with a background as POA diffuse, shifting gas-particle partitioning of monosaccharides to the gasphase. ${ }^{3}$ As the gas-phase oxidation can alter the gas-particle equilibrium, particle-phase species will further evaporate to maintain phase equilibrium. Even a small fraction of gas-phase species will induce additional oxidation. ${ }^{13}$ Therefore, the $C_{\mathrm{G}} /$ $C_{p}$ will change as POA emissions leave the sources.

Considering the atmospheric conditions, particle-phase liquid water has been observed to play the predominant role in the gas/particle partitioning of water-soluble organic matter in the eastern U.S.A. ${ }^{42}$ In this study, humidity was found to be closely negative related to the total concentration of levoglucosan $(p<0.05)$ and mannosan $(p<0.01)$, as well as the gas- and particle-phases of levoglucosan $(p<0.05)$, implying the high relative humidity would influence the gasparticle partitioning and promote more gas-phase monosaccharides. This might probably due to the solubility of levoglucosan in the liquid water content of aerosol, which was related to humidity. ${ }^{43}$ The impact of ambient temperature on $\phi_{\mathrm{p}}$ was negligible due to the small variations in the temperature during the study period. ${ }^{44,45}$ Thus, the particle phase fraction of monosaccharides in Guangzhou was primarily driven by humidity or particle-phase liquid water. Information about the correlations with other daily basic environmental parameters is shown in Table S8.

3.1.2. Degradation of Monosaccharides in PUF-PAS. In this study, the average recovery of spiked ${ }^{13} \mathrm{C}_{6}$ levoglucosan in PUF disks varied from $81 \pm 0.0 \%$ to $98 \pm 1.6 \%$ in different retrieval periods (Figure S1), indicating a stability of monosaccharides on PUFs. Degradation can be neglected over a long-time deployment up to 92 days, with the effective protection of PAS from the degradation of atmospheric 
oxidants in the ambient atmosphere. ${ }^{6,46}$ Some laboratory studies reported that the semivolatile molecular markers would rapidly decay (0.2-3.6 days) when undergoing accelerated chemical oxidation under average summertime conditions and different environmental conditions. ${ }^{13,47,48}$ However, the previous work has shown that levoglucosan remains stable over a period of around 10 days under the exposure to ambient levels of sulfate acid and some photochemical oxidants, such as ozone and gaseous nitrogen dioxide. ${ }^{6}$ Moreover, the concentrations of oxidants in the real atmosphere are discrepant with those monitored in laboratory, which might be much lower than the critical values detected under a laboratory condition. For example, levoglucosan is unlikely to undergo significant decay considering winter synoptic conditions and estimated $\mathrm{OH}$ concentrations $\left(<1 \times 10^{6}\right.$ molecules $\left./ \mathrm{cm}^{3}\right) .{ }^{49}$

Actually, the most atmospheric reactive species had already been reacted to the freshly emitted active monosaccharides prior to collection, making particles less available for further degradations. ${ }^{46}$ Moreover, the structure of PUF-PAS might be helpful for the "reservation" of monosaccharides. The effect of the diffusion of oxidant gases on the PUF-PAS is much slower than the diffusivity in the air and is limited to a $<1 \mathrm{~cm}$ penetration into the PUF. ${ }^{50}$ Also, the protective structure of the shielded particle made them less available for further degradation. ${ }^{4,51}$ Therefore, with the protection of the doubledomed chambers of PAS, degrading factors were further reduced. ${ }^{27}$ Monosaccharides could be considered stable and hardly revolatile when they are once collected on the PUFPAS.

3.1.3. Accumulation of Monosaccharides in PUF-PAS. The capture of monosaccharides by the PUF-PAS increased linearly over 73 days (Table S3 and Figure S2). The linear uptake stage time was comparable with that during 2-9 weeks for the particle-bound PAHs. ${ }^{52}$ The three monosaccharides in the PUF-PAS likely approached the curvilinear uptake stage after the 73-day exposure. Thus, to maintain linear uptake conditions of passive sampling for monosaccharides, the field sampling time is suggested to be no more than 70 days. The uptake of a target compound by PUF-PAS is based on the following equation:

$$
V_{\mathrm{S}}\left(\frac{\mathrm{d} C_{\mathrm{S}}}{\mathrm{d} t}\right)=k_{\mathrm{o}} A_{\mathrm{S}}\left(\frac{C_{\mathrm{A}}-C_{\mathrm{S}}}{K_{\mathrm{SA}}}\right)
$$

where $V_{\mathrm{S}}$ is the volume of PUF; $C_{\mathrm{S}}$ and $C_{\mathrm{A}}$ are the concentrations of analyte in PUF-PAS and air, respectively; $k_{0}$ is the overall mass transfer coefficient; $A_{\mathrm{S}}$ is the superficial area of PUF; and $K_{\mathrm{SA}}$ is the PUF/air partition coefficient, which is related to $K_{\mathrm{OA}} \cdot{ }^{40}$ Among these parameters, $V_{\mathrm{S}}, A_{\mathrm{S}}$, and $K_{\mathrm{SA}}$ are related to the uptake and sampling rates of target compounds by PUF-PAS. ${ }^{21}$ The volume $\left(V_{\mathrm{S}}\right)$ and the superficial area $\left(A_{\mathrm{S}}\right)$ of PUF used in the current study are as the same as the studies of Shoeib and Harner (2002) and Wilford et al. (2004), while the linear phase region would be different when comparing to other PUFs. As the function of temperature, for nonpolar POPs, $K_{\mathrm{SA}}$ has been estimated according to a relationship between $K_{\mathrm{SA}}$ and $K_{\mathrm{OA}}$, which will increase by a factor of about 3 for every $10{ }^{\circ} \mathrm{C}$ drop in temperature, ${ }^{40}$ thus increasing the linear phase region of PUF-PAS. Regardless of the polar characteristics of monosaccharides, however, during the calibration exercise, the daily temperature all ranged within
$10{ }^{\circ} \mathrm{C}$, and the average daily temperature varied within a small range. Thus, the influence of temperature could be ignored.

3.1.4. Air Sampling Rates for Monosaccharides. According to eq 2 , when the term $C_{S} / K_{\mathrm{SA}}$ is small, it is linear accumulation stage, the equivalent air volumes $\left(V_{\mathrm{eq}}, \mathrm{m}^{3}\right)$ of the PAS samples plotted against the given exposure period (d) were based on the following: ${ }^{40}$

$$
V_{\mathrm{eq}}=\frac{M}{C_{\mathrm{A}}}=R T
$$

where $M$ is the daily accumulated mass of target compound collected by each PUF disk during the exposure period $(M$, $\mathrm{ng} / \mathrm{d}) ; C_{\mathrm{A}}$ is the daily air concentration of target compound measured by AAS (gas + particle phase) during the corresponding deployment time of PUF-PAS $\left(C_{A}, \mathrm{ng} / \mathrm{m}^{3} /\right.$ d); $T$ is the exposure time of the PUF disk; and $R$ was the sampling rate of PUF disk over the uptake phase $\left(R, \mathrm{~m}^{3} / \mathrm{d}\right)$. Each pair of PAS-AAS data for the target compound could be used to build an equation to calculate the $V_{\text {eq }}$ for each period, using the above equation (Table S9).

Linear uptakes of monosaccharides for PUF-PAS over the calibration exercise period were found by good linear correlations between the values of $V_{\text {eq }}$ and $T$ within 73 days. The accumulated rates over the entire linear uptake phase were determined by the slope of the obtained linear regression plots between $V_{\text {eq }}$ and $T$ within 73 days, reflecting the average $R$ for the first 4 deployment intervals (without the 92-day results) (Figure 2). The sampling rates of monosaccharides were 1.1 $\mathrm{m}^{3} / \mathrm{d}$ for levoglucosan (Figure 2a) and galactosan (Figure $2 \mathrm{c}$ ), and $1.5 \mathrm{~m}^{3} / \mathrm{d}$ for mannosan (Figure $2 \mathrm{~b}$ ), respectively. Due to hemicellulose being less structured compared to cellulose, 7,53 hemicellulose thermal decomposition products, such as mannosan, were presumed to be more readily captured by the PUF, therefore resulting in a relatively higher sampling rate. Although the PUF-PAS sampling rates of monosaccharides are not as high as those of mainly gas-phase SVOCs including PCBs, OCPs, and PBDEs, which usually take the sampling rate range of $3-4 \mathrm{~m}^{3} / \mathrm{d},{ }^{40,54}$ they are comparable with those of reported particle associated SVOCs. For example, the PUF-PAS sampling rates for monosaccharides were slightly higher than those for the particle associated PAHs detected in the southern Czech Republic $\left(\sim 0.7 \mathrm{~m}^{3} / \mathrm{d}\right)^{26}$ and nonindustrial indoor environments $\left(0.2-0.9 \mathrm{~m}^{3} / \mathrm{d}\right),{ }^{52}$ and were comparable to the measured average rates for the PCDDs/Fs (1.4-2 $\left.\mathrm{m}^{3} / \mathrm{d}\right)$, which were also mainly particlebound, detected in South Korea and Spain. ${ }^{55,56}$ Generally, the PUF-PAS sampling rate of particle-associated SVOCs were lower than those of the gaseous phase dominant SVOCs, but at the same order of magnitude for both gas-phase and particleassociated SVOCs. ${ }^{20,50}$ It has to be mentioned that the reported $R$ was derived by different passive samplers. A recent study evaluated particle infiltration efficiencies (PIEs) of PUF-PAS of several popular designs. The varied PIEs from $\sim 54 \%$ to $103 \%$ may lead to varied particle collection efficiency of PUF-PAS in different designs. ${ }^{32}$ It is speculated that the larger interior volume of the sampler chamber than the air exchange capacity would probably lower the PIEs. ${ }^{32}$ For our current sampler, the internal volume of $\sim 5200 \mathrm{~cm}^{3}$ and the ratio of internal volume and gap surface area of $\sim 36\left(\mathrm{~cm}^{3} /\right.$ $\mathrm{cm}^{2}$ ), are between those of LANCS and MONET samplers (Table S1), which might be one of the reasons for the low $R$.

Likewise, sampling rates are not only influenced by the physicochemical properties of the target compounds, the 


\section{Levoglucosan}
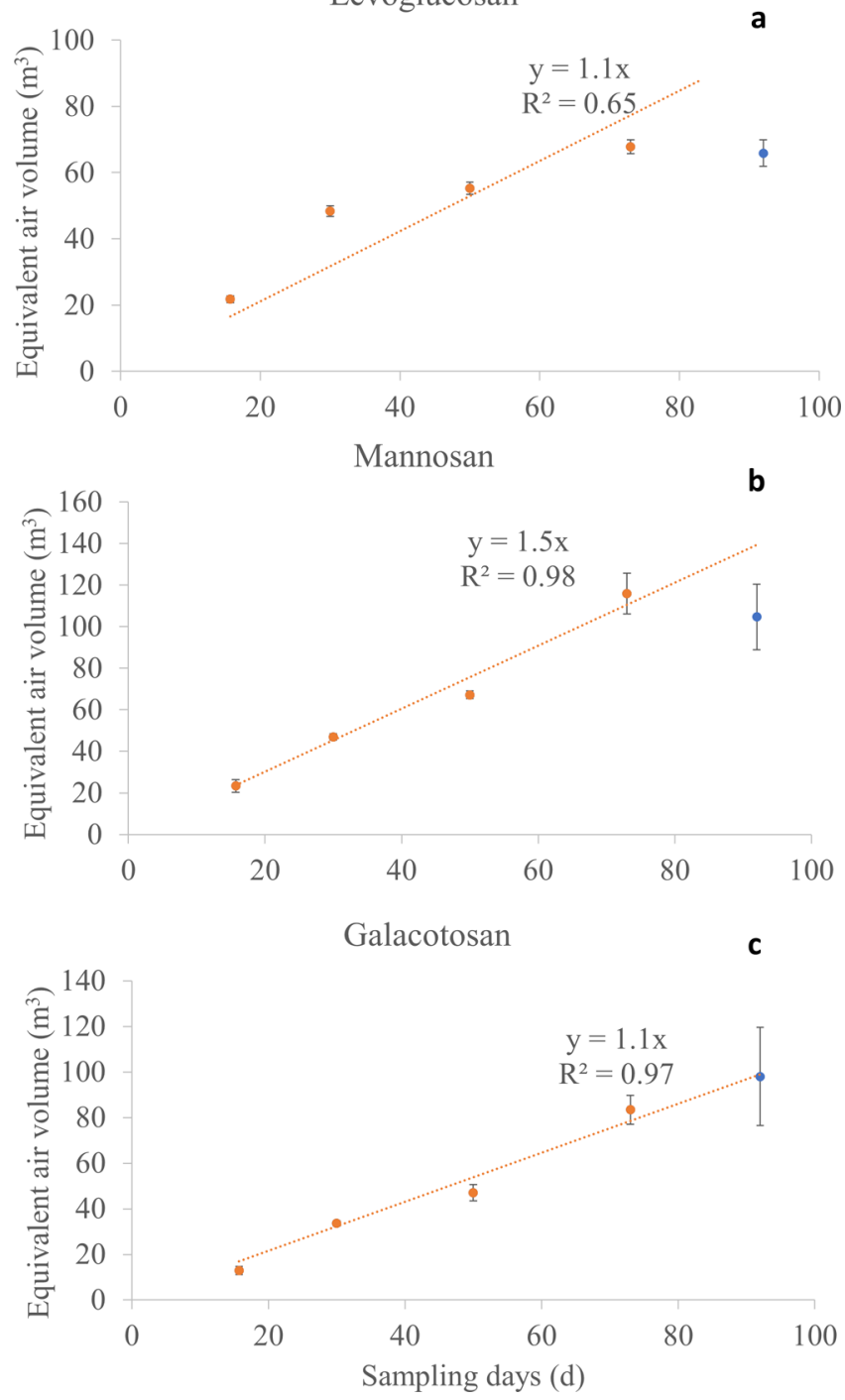

Figure 2. Equivalent air volume sampled for monosaccharides using PUF disks over the 92-day deployment. superficial area and the volume of the PUF, the design of sampler, but also by the atmospheric conditions and meteorological parameters, such as wind speed, temperature, humidity, and aerosol concentration. ${ }^{26,38,39}$ For specific compounds, sampling rates could be varied in different regions. Some previous papers mentioned high sampling rates of particle-associated polycyclic aromatic compounds (PACs) $\left(5-8 \mathrm{~m}^{3} / \mathrm{d}\right)$ in Canada, ${ }^{21,31}$ and even higher sampling rates of particle-associated PAHs than those of some gaseous PAHs in a furnace area of alloy factory, an occupational environment $\left(1.3-10 \mathrm{~m}^{3} / \mathrm{d}\right){ }^{20}$ As mentioned above, the gasparticle equilibrium of monosaccharides might be influenced by the particle-phase liquid water. ${ }^{15}$ The air humidity in Southern China is generally higher than that of the high latitude areas and countries, might become one of the important reasons contributing to the low sampling rates of monosaccharides in this area. Moreover, sampling rates were found as a function of wind speed. ${ }^{21,26,57}$ Higher wind speeds $(>5 \mathrm{~m} / \mathrm{s})$ would experience nonlinear aerodynamics and approach to chemical equilibrium rapidly. ${ }^{57}$ When the wind speed is higher than $4 \mathrm{~m} / \mathrm{s}$, fine particles can form clusters of larger size inside the PUF, ${ }^{58}$ which would decrease the sampling rates of particle-bound compounds. ${ }^{26}$ In this study, the wind speed was mostly lower than $3.3 \mathrm{~m} / \mathrm{s}$ during the calibration study, which could be regarded as low wind speed (Table S2). Besides, with the low wind speed, wind direction changing would not greatly influence the time-weighted average (TWA) concentrations of monosaccharides in a region.

Besides the above uncertainties of sampling rates, other potential sources might also cause the propagated errors. For example, the variable air concentrations of monosaccharides might be brought by the less well-mixed air from the accidental occurrences of fire episodes. Keeping the sampling sites far away from the $\mathrm{BB}$ point sources, could greatly avoid the interruption of accidental fire occurrences during the sampling campaign. Although the high temperature in summer would facilitate the evaporation of monosaccharides, the breakthrough of monosaccharides only occupied less than $3 \%$ of the total concentrations of monosaccharides tested by the 7 day continuous active sampling. The negligible breakthrough

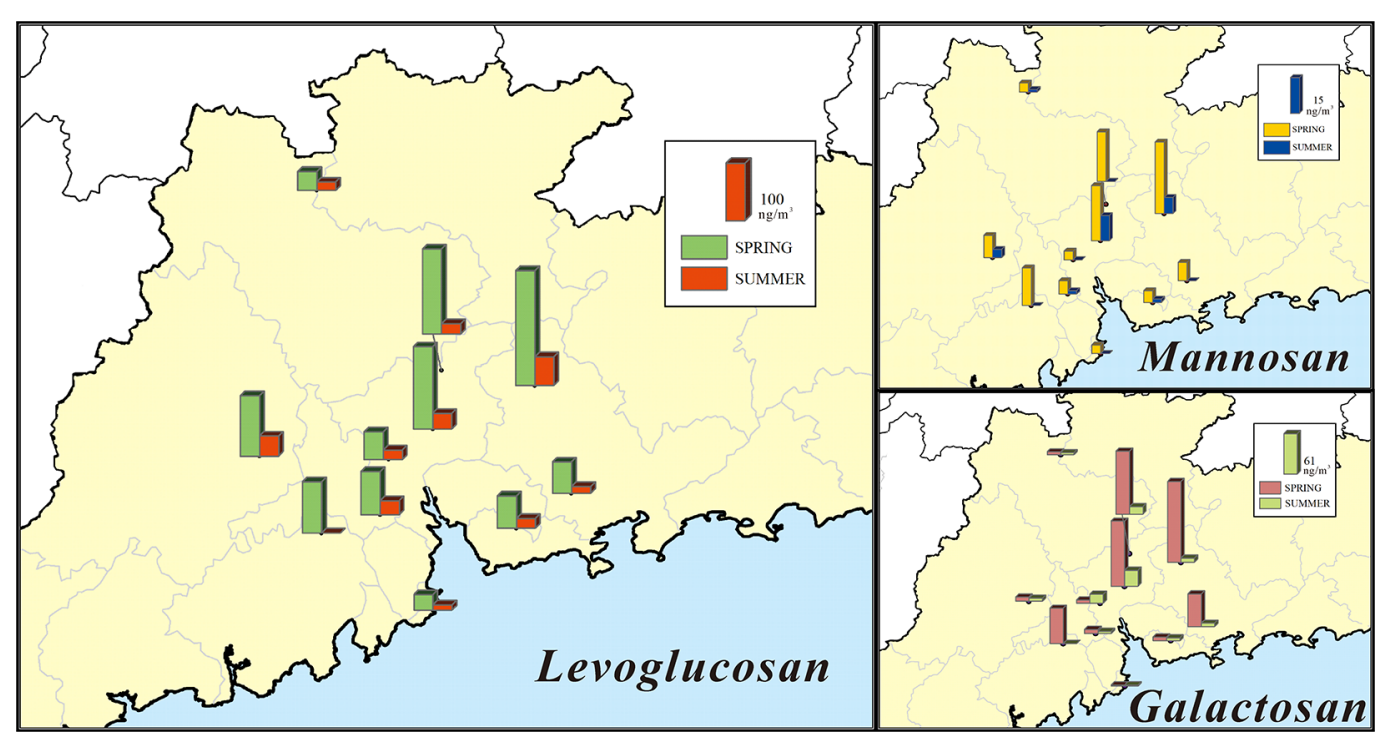

Figure 3. Spatial and seasonal distribution of monosaccharides in the Pearl River Delta. 
value probably due to the low concentrations of monosaccharides and good air quality during the summer of Guangzhou.

Lower $V_{\text {eq }}$ values of $\sim 80 \mathrm{~m}^{3}$ were derived for particle-phase levoglucosan over the 73-day deployment, compared to $\sim 420$ $\mathrm{m}^{3}$ for gas-phase levoglucosan, suggesting that approximately $20 \%$ of the ambient particles were sampled by the PUF disk. It was higher than that of the previous estimation of $10 \%$ ambient particles sampled by PUF disk. ${ }^{26}$ Besides, previous studies have shown that the agreements between the AAS and the PAS data for mainly particle-associated species were well within a factor of $2-3,{ }^{2,30,55,56}$ suggesting the PUF-PAS offers a feasible alternative to AAS when assessing the ambient concentrations of monosaccharides. Therefore, it is appropriate to apply the PUF-PAS to examine spatial patterns of monosaccharides at a regional scale.

3.2. Spatial Distribution of Monosaccharides. Since there were no distinct differences of the atmospheric conditions and meteorological parameters between the periods of PRD sampling campaigns and calibration exercise, (Tables S2 and S5), and no unusual events occurred around the sampling sites during the sampling campaigns, the derived sampling rates of PUF-PAS for monosaccharides could be directly applied in the PRD region. On the basis of the derived sampling rate, a spatial map of monosaccharide air concentrations across the PRD is shown in Figure 3 and Table S10. In the present study, the detected concentrations of levoglucosan (L), mannosan (M), and galactosan (G) in JanApr had ranges of $28(\mathrm{ZH})-200(\mathrm{BL}) \mathrm{ng} / \mathrm{m}^{3}, 3.4(\mathrm{ZH})-29$ $(\mathrm{BL}) \mathrm{ng} / \mathrm{m}^{3}$, and $1.9(\mathrm{ZH})-120(\mathrm{BL}) \mathrm{ng} / \mathrm{m}^{3}$, with means of 91 $\pm 56 \mathrm{ng} / \mathrm{m}^{3}(\mathrm{~L}), 11 \pm 8.8 \mathrm{ng} / \mathrm{m}^{3}(\mathrm{M})$, and $41 \pm 46 \mathrm{ng} / \mathrm{m}^{3}(\mathrm{G})$, respectively. However, in Jul-Sep, concentrations decreased to the ranges of $10(\mathrm{ZH})-51(\mathrm{BL}) \mathrm{ng} / \mathrm{m}^{3}(\mathrm{~L}), 1.1(\mathrm{TJ})-10(\mathrm{JL})$ $\mathrm{ng} / \mathrm{m}^{3}(\mathrm{M})$, and $1.8(\mathrm{ZH})-24(\mathrm{JL}) \mathrm{ng} / \mathrm{m}^{3}(\mathrm{G})$, with average values of $23 \pm 13 \mathrm{ng} / \mathrm{m}^{3}(\mathrm{~L}), 3.9 \pm 3.6 \mathrm{ng} / \mathrm{m}^{3}(\mathrm{M})$, and $7.7 \pm$ $6.8 \mathrm{ng} / \mathrm{m}^{3}(\mathrm{G})$, respectively. These results are comparable with the concentrations of monosaccharides previously detected in Guangzhou and the PRD in recent years. Likewise, lower concentrations of monosaccharides were found in summer or in wet seasons compared to those in other periods (Table S11). ${ }^{34,59-61}$ Most of the previous studies were conducted on $\mathrm{PM}_{2.5}$ samples, which were different from the current study of the PUF disks samples that both of the gas and particle-phases of the target compounds were collected. ${ }^{25}$ However, these results are still of highly referable meanings, suggesting that the estimates of air concentrations derived from the PUF-PAS are reliable.

It is noteworthy that the detected concentrations of galactosan were higher than mannosan concentrations in Jan-Apr in the PRD area of present study, which is in agreement with the other studies on smoke particles derived from environmental samples ${ }^{62}$ and source samples, such as the combustion of rice straws, biomass briquettes, and grasses, ${ }^{63}$ suggesting that agricultural waste was the primary biomass burning product. ${ }^{62}$ Generally, concentrations of levoglucosan in the PRD were lower than those of the North China Plain ${ }^{62,64}$ and comparable with those of western Europe (Table S11). ${ }^{8}$

Among the sampling sites of the present study, the background site (TJ) had concentrations of $34 \mathrm{ng} / \mathrm{m}^{3}(\mathrm{~L})$, $3.6 \mathrm{ng} / \mathrm{m}^{3}(\mathrm{M})$, and $4.3 \mathrm{ng} / \mathrm{m}^{3}(\mathrm{G})$ in Jan-Apr and $15 \mathrm{ng} / \mathrm{m}^{3}$ (L), $1.1 \mathrm{ng} / \mathrm{m}^{3}(\mathrm{M})$ and $3.1 \mathrm{ng} / \mathrm{m}^{3}$ (G) in Jul-Sep, which were all higher than the western North Pacific rim maritime background in both seasons. ${ }^{65}$ The background concentration of levoglucosan was higher than the biannual average concentration of Atlantic maritime aerosols and high-altitude mountain background sites as well, but lower than the lowaltitude coastal and continental rural sites in Europe (Table S11). ${ }^{66}$ As expected, the concentrations of monosaccharides in rural areas were higher than those in urban areas in this study (Table S10). ${ }^{59}$ The highest concentrations of monosaccharides in Jan-Apr were found at the BL site, which is located at a village bordering the city in the eastern $\mathrm{PRD}$ and surrounded by paddy fields and woods, followed by two suburban sites, $\mathrm{CH}$ and JL. The lowest concentrations were found at a coastal city $(\mathrm{ZH})$ and a background site $(\mathrm{TJ}) . \mathrm{ZH}$ was considered a background site of the PRD region in the previous study, due to the good air quality throughout most of the year. ${ }^{34}$

The ratio of levoglucosan to mannosan (L/M) has been proposed as an indicator for different types of biomass fuels, and the ratio typically ranges from 2 to 6 for softwoods but stays in a higher values, 13 to 35 , for hardwoods. ${ }^{67}$ In this study, the ratios of $\mathrm{L} / \mathrm{M}$ were found to be similar in both seasons for specific areas (Table S10). However, the values for urban areas were distinct from those of rural areas. With the exception of $\mathrm{ZH}$, the $\mathrm{L} / \mathrm{M}$ of urban areas had a range of $12-$ 19 , while the rural areas had a range of $2.8-7.9$, with average ratios of $14 \pm 2.7$ and $6.5 \pm 1.8$, respectively. The results suggest that both areas were likely affected by a mixture of biomass burning emissions. Urban areas might be mainly influenced by hardwood, peat (11.4), and weed combustion $(8-16),{ }^{34,60}$ while rural areas might be possibly affected by softwood combustion and agricultural residues, such as leaves (5.5), weed, sugar cane, and bamboo (5-13). ${ }^{60,67}$

3.3. Relationships between Fire Activities and Concentrations of Monosaccharides derived by PUFPAS. To evaluate the impacts of fire activities at each sampling site, a numerical model was established to count fire activities based on the MODIS data within a $50 \mathrm{Km}$ radius centered on the sampling sites (Table S12). Significant correlations $(n=$ $11, p<0.01$ ) were found between the concentrations of monosaccharides and the number of fire activities corresponding to each sampling site in Jan-Apr (Figure 4). This result further suggested that it was practical to monitor monosaccharides in air by using PUF-PAS. Besides, open BB intensity in PRD was reflected well by monosaccharide levels in Jan-Apr. However, in Jul-Sep, no significant correlation was observed between the concentrations of monosaccharides and the number of fire activities corresponding to each sampling site, which means open BB intensity was not reflected well by monosaccharide levels. Although there was an obvious increase in fire activities noted by MODIS image, lower monosaccharides concentrations were observed by PUF-PAS in Jul-Sep than in Jan-Apr. This phenomenon is probably due to Jul-Sep meteorological conditions, excluding emission and reaction rates. In Jul-Sep, for example, warm and damp air masses from the South China Sea bring frequent precipitation and high humidity, and the strong intensity of solar radiation increases the degradation of monosaccharides during air transport before being collected by the PUF-PAS. ${ }^{60,68}$ Moreover, high temperature induces thermal convection and the high mixing layer favors the diffusion and dilution of biomass burning smoke. ${ }^{61}$ Thus, these major meteorological factors result in lower concentrations observed in Jul-Sep compared to other periods. ${ }^{60,64}$ Anyhow, this phenomenon reveals that the feasibility of PUF-PAS does not have to mean 
Levoglucosan
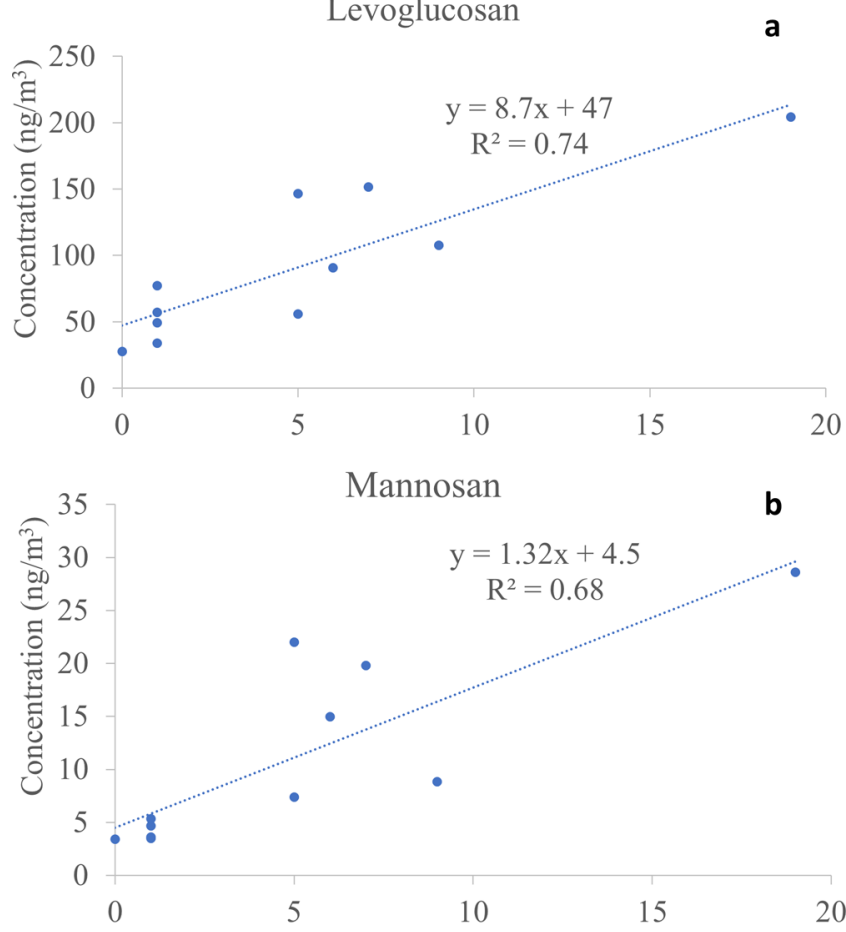

Galactosan

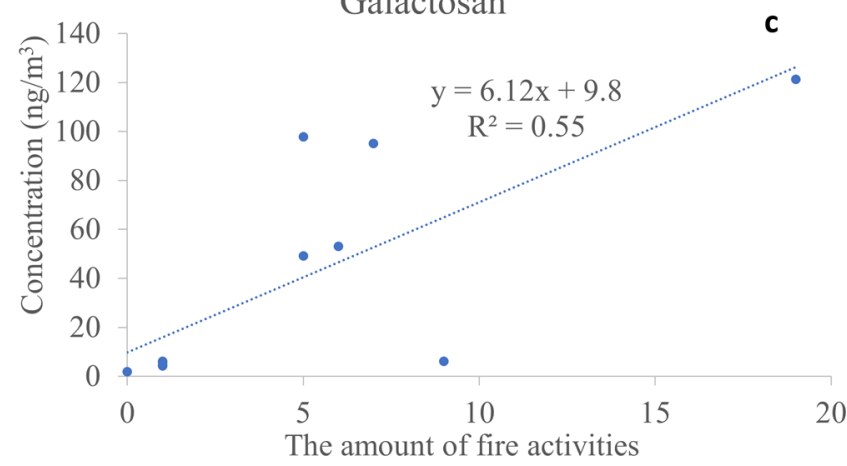

Figure 4. Correlations between fire activities and concentrations of monosaccharides in Jan-Apr of Pearl River Delta.

that MODIS fire activities are reflected well by monosaccharide concentrations derived from PUF-PASs.

$\mathrm{BB}$ often occurs accidentally and in backcountry, which increases the difficulties of "capturing" fire emissions over time. With the feasibility and application of PUF-PAS monitoring monosaccharides, TWA concentrations of monosaccharides at a regional scale are acquired. The relevant data on regional field combustion, and biomass burning information, combustion types and health assessments, would be helpful for subsequent studies on the validation of biomass burning prediction by models such as MODIS and developing fires inventories. ${ }^{69,70}$ Moreover, it provides the valuable information between biomass burning source regions and target regions via long-range transportation and migration. ${ }^{71}$

\section{ASSOCIATED CONTENT}

\section{S Supporting Information}

. The Supporting Information is available free of charge on the ACS Publications website at DOI: 10.1021/acs.est.8b02254.

(Section S1) Extraction, derivatization, and GC-MS analysis. (Section S2) Concentrations of monosaccharides in the AAS samples. (Section S3) Tables and figures: (Table S1) information of the sampler used in the current study and comparison with three commonly used PUF-PASs; (Table S2) basic environmental and meteorological parameters during the calibration exercise; (Table S3) sampling date and mass of monosaccharides collected by PUF-PAS; (Table S4) information of the sampling sites in the PRD region; (Table S5) basic environmental and meteorological parameters during the sampling campaigns in the PRD region; (Table S6) concentrations of monosaccharides from the AAS measurement; (Table S7) particle-phase fraction parameter $(\phi \mathrm{p})$ and the ratio of gas- to particlephase for monosaccharides; (Table S8) correlations between monosaccharides and basic environmental parameters; (Table S9) calculation results of equivalent air volume and accumulated sampling rates; (Table S10) concentrations of monosaccharides in the PRD region; (Table S11) concentrations of monosaccharides in the references; (Table S12) Amount of fire activities within a $50 \mathrm{Km}$ radius centered on the sampling sites; (Figure S1) Recoveries of spiked ${ }^{13} \mathrm{C}_{6}$ levoglucosan in PUF disks over the 92-day deployment; (Figure S2) Accumulated amounts of monosaccharides in the PUF-PAS over the 92-day deployment; (Figure S3) Total concentrations and gas- and particle-phase concentrations of monosaccharides derived by active sampling; (Figure S4) Variations in monosaccharides, the particle-phase fraction parameter $\left(\phi_{\mathrm{p}}\right)$, organic matter $(\mathrm{OM})$, total suspended particulates (TSP) and relative humidity (RH) during the calibration exercise; and (Figure S5) Correlations between daily air concentrations derived by active sampling and daily accumulated amounts derived by PUF-PAS during each period (PDF)

\section{AUTHOR INFORMATION}

\section{Corresponding Authors}

*Tel.: (86) 20 85290800; fax:(86) 20 85290706; e-mail: zhanggan@gig.ac.cn (G.Zha.).

*Tel.: (86) 20 38350480; fax: (86) 20 85290706; e-mail: gczhong@gig.ac.cn (G.Zho.).

\section{ORCID $\odot$}

Guangcai Zhong: 0000-0002-5647-5940

Chongguo Tian: 0000-0001-6058-9353

Jun Li: 0000-0002-3637-1642

Zhiqiang Yu: 0000-0002-8631-2704

Lidia Morawska: 0000-0002-0594-9683

Gan Zhang: 0000-0002-9010-8140

\section{Notes}

The authors declare no competing financial interest.

\section{ACKNOWLEDGMENTS}

This study was supported by the Natural Science Foundation of China (NSFC; Nos. 41430645 and 41390240), the National Key R\&D Program of China (2014BAC22B04 and 2017YFC0212000) and the International Partnership Program of Chinese Academy of Sciences (Grant No. 132744KYSB20170002). The authors thank Yankuan Tian and Kechang Li for their assistance in the lab analysis, and Jiangtao Li for his backing in precleaning PUF disks. This is a contribution of the GIGCAS No.IS-2593. 


\section{REFERENCES}

(1) He, C.; Miljevic, B.; Crilley, L. R.; Surawski, N. C.; Bartsch, J.; Salimi, F.; Uhde, E.; Schnelle-Kreis, J.; Orasche, J.; Ristovski, Z.; Ayoko, G. A.; Zimmermann, R.; Morawska, L. Characterisation of the impact of open biomass burning on urban air quality in Brisbane, Australia. Environ. Int. 2016, 91, 230-42.

(2) Milic, A.; Mallet, M. D.; Cravigan, L. T.; Alroe, J.; Ristovski, Z. D.; Selleck, P.; Lawson, S. J.; Ward, J.; Desservettaz, M. J.; PatonWalsh, C.; Williams, L. R.; Keywood, M. D.; Miljevic, B. Aging of aerosols emitted from biomass burning in northern Australia. Atmos. Chem. Phys. Discuss. 2016, 1-24.

(3) Andreae, M. O.; Merlet, P. Emission of trace gases and aerosols from biomass burning. Global Biogeochem. Cycles 2001, 15 (4), 955966.

(4) Crutzen, P. J.; Andreae, M. O. BIOMASS BURNING IN THE TROPICS - IMPACT ON ATMOSPHERIC CHEMISTRY AND BIOGEOCHEMICAL CYCLES. Science 1990, 250 (4988), 16691678.

(5) Yadav, I. C.; Devi, N. L.; Li, J.; Syed, J. H.; Zhang, G.; Watanabe, $\mathrm{H}$. Biomass burning in Indo-China peninsula and its impacts on regional air quality and global climate change-a review. Environ. Pollut. 2017, 227, 414-427.

(6) Fraser, M. P.; Lakshmanan, K. Using levoglucosan as a molecular marker for the long-range transport of biomass combustion aerosols. Environ. Sci. Technol. 2000, 34 (21), 4560-4564.

(7) Simoneit, B. R. T. Biomass burning - A review of organic tracers for smoke from incomplete combustion. Appl. Geochem. 2002, 17 (3), $129-162$.

(8) Cordell, R. L.; Mazet, M.; Dechoux, C.; Hama, S. M. L.; Staelens, J.; Hofman, J.; Stroobants, C.; Roekens, E.; Kos, G. P. A.; Weijers, E. P.; Frumau, K. F. A.; Panteliadis, P.; Delaunay, T.; Wyche, K. P.; Monks, P. S. Evaluation of biomass burning across North West Europe and its impact on air quality. Atmos. Environ. 2016, 141, 276286.

(9) Simoneit, B. R. T.; Schauer, J. J.; Nolte, C. G.; Oros, D. R.; Elias, V. O.; Fraser, M. P.; Rogge, W. F.; Cass, G. R. Levoglucosan, a tracer for cellulose in biomass burning and atmospheric particles. Atmos. Environ. 1999, 33 (2), 173-182.

(10) Graham, B.; Mayol-Bracero, O. L.; Guyon, P.; Roberts, G. C.; Decesari, S.; Facchini, M. C.; Artaxo, P.; Maenhaut, W.; Koll, P.; Andreae, M. O. Water-soluble organic compounds in biomass burning aerosols over Amazonia-1. Characterization by NMR and GC-MS. J. Geophys. Res. 2002, 107 (D20), LBA-14 DOI: 10.1029/ 2001JD000336.

(11) Simoneit, B. R. T. Composition and major sources of organic compounds of aerosol particulate matter sampled during the ACEAsia campaign. J. Geophys. Res. 2004, 109 (D19) DOI: 10.1029/ 2004JD004598.

(12) Liu, J.; Li, J.; Zhang, Y.; Liu, D.; Ding, P.; Shen, C.; Shen, K.; He, Q.; Ding, X.; Wang, X.; Chen, D.; Szidat, S.; Zhang, G. Source apportionment using radiocarbon and organic tracers for PM2.5 carbonaceous aerosols in Guangzhou, South China: contrasting localand regional-scale haze events. Environ. Sci. Technol. 2014, 48 (20), $12002-11$.

(13) May, A. A.; Saleh, R.; Hennigan, C. J.; Donahue, N. M.; Robinson, A. L. Volatility of Organic Molecular Markers Used for Source Apportionment Analysis: Measurements and Implications for Atmospheric Lifetime. Environ. Sci. Technol. 2012, 46 (22), 1243512444.

(14) Booth, A.; Montague, W.; Barley, M.; Topping, D.; McFiggans, G.; Garforth, A.; Percival, C. Solid state and sub-cooled liquid vapour pressures of cyclic aliphatic dicarboxylic acids. Atmos. Chem. Phys. 2011, 11 (2), 655-665.

(15) Xie, M.; Hannigan, M. P.; Barsanti, K. C. Gas/Particle Partitioning of 2-Methyltetrols and Levoglucosan at an Urban Site in Denver. Environ. Sci. Technol. 2014, 48 (5), 2835-2842.

(16) Grieshop, A. P.; Logue, J. M.; Donahue, N. M.; Robinson, A. L. Laboratory investigation of photochemical oxidation of organic aerosol from wood fires 1: measurement and simulation of organic aerosol evolution. Atmos. Chem. Phys. 2009, 9 (4), 1263-1277.

(17) Oja, V.; Suuberg, E. M. Vapor pressures and enthalpies of sublimation of D-glucose, D-xylose, cellobiose, and levoglucosan. J. Chem. Eng. Data 1999, 44 (1), 26-29.

(18) Shiu, W.-Y.; Mackay, D.; Ma, K.-C.; Lee, S. C. Handbook of Physical-Chemical Properties and Environmental Fate for Organic Chemicals; CRC Press: 2006.

(19) Jaward, F. M.; Zhang, G.; Nam, J. J.; Sweetman, A. J.; Obbard, J. P.; Kobara, Y.; Jones, K. C. Passive air sampling of polychlorinated biphenyls, organochlorine compounds, and polybrominated diphenyl ethers across Asia. Environ. Sci. Technol. 2005, 39 (22), 8638-45.

(20) Bohlin, P.; Jones, K. C.; Strandberg, B. Field evaluation of polyurethane foam passive air samplers to assess airborne PAHs in occupational environments. Environ. Sci. Technol. 2010, 44 (2), 749754.

(21) Melymuk, L.; Robson, M.; Helm, P. A.; Diamond, M. L. Evaluation of passive air sampler calibrations: Selection of sampling rates and implications for the measurement of persistent organic pollutants in air. Atmos. Environ. 2011, 45 (10), 1867-1875.

(22) Jaward, F. M.; Farrar, N. J.; Harner, T.; Sweetman, A. J.; Jones, K. C. Passive air sampling of polycyclic aromatic hydrocarbons and polychlorinated naphthalenes across Europe. Environ. Toxicol. Chem. 2004, 23 (6), 1355-1364.

(23) Cheng, H.; Deng, Z.; Chakraborty, P.; Liu, D.; Zhang, R.; Xu, Y.; Luo, C.; Zhang, G.; Li, J. A comparison study of atmospheric polycyclic aromatic hydrocarbons in three Indian cities using PUF disk passive air samplers. Atmos. Environ. 2013, 73, 16-21.

(24) Wang, X.-p.; Gong, P.; Yao, T.-d.; Jones, K. C. Passive air sampling of organochlorine pesticides, polychlorinated biphenyls, and polybrominated diphenyl ethers across the Tibetan Plateau. Environ. Sci. Technol. 2010, 44 (8), 2988-2993.

(25) Wilford, B. H.; Harner, T.; Zhu, J.; Shoeib, M.; Jones, K. C. Passive sampling survey of polybrominated diphenyl ether flame retardants in indoor and outdoor air in Ottawa, Canada: implications for sources and exposure. Environ. Sci. Technol. 2004, 38 (20), 53125318.

(26) Klanova, J.; Eupr, P.; Kohoutek, J.; Harner, T. Assessing the influence of meteorological parameters on the performance of polyurethane foam-based passive air samplers. Environ. Sci. Technol. 2008, 42 (2), 550-5.

(27) Harner, T.; Shoeib, M.; Diamond, M.; Stern, G.; Rosenberg, B. Using passive air samplers to assess urban-rural trends for persistent organic pollutants. 1. Polychlorinated biphenyls and organochlorine pesticides. Environ. Sci. Technol. 2004, 38 (17), 4474-4483.

(28) Motelay-Massei, A.; Harner, T.; Shoeib, M.; Diamond, M.; Stern, G.; Rosenberg, B. Using passive air samplers to assess urbanrural trends for persistent organic pollutants and polycyclic aromatic hydrocarbons. 2. seasonal trends for PAHs, PCBs, and organochlorine pesticides. Environ. Sci. Technol. 2005, 39 (15), 5763-5773.

(29) Pozo, K.; Harner, T.; Shoeib, M.; Urrutia, R.; Barra, R.; Parra, O.; Focardi, S. Passive-sampler derived air concentrations of persistent organic pollutants on a North- South transect in Chile. Environ. Sci. Technol. 2004, 38 (24), 6529-6537.

(30) Kalina, J.; Scheringer, M.; Boruvkova, J.; Kukucka, P.; Přibylová, P.; Bohlin-Nizzetto, P.; Klánová, J. Passive air samplers as a tool for assessing long-term trends in atmospheric concentrations of semivolatile organic compounds. Environ. Sci. Technol. 2017, 51 (12), $7047-7054$

(31) Harner, T.; Su, K.; Genualdi, S.; Karpowicz, J.; Ahrens, L.; Mihele, C.; Schuster, J.; Charland, J.-P.; Narayan, J. Calibration and application of PUF disk passive air samplers for tracking polycyclic aromatic compounds (PACs). Atmos. Environ. 2013, 75, 123-128.

(32) Markovic, M. Z.; Prokop, S.; Staebler, R. M.; Liggio, J.; Harner, $\mathrm{T}$. Evaluation of the particle infiltration efficiency of three passive samplers and the PS-1 active air sampler. Atmos. Environ. 2015, 112, 289-293.

(33) Chaemfa, C.; Barber, J. L.; Moeckel, C.; Gocht, T.; Harner, T.; Holoubek, I.; Klanova, J.; Jones, K. C. Field calibration of 
polyurethane foam disk passive air samplers for PBDEs. J. Environ. Monit. 2009, 11 (10), 1859-1865.

(34) Zhang, Z.; Gao, J.; Engling, G.; Tao, J.; Chai, F.; Zhang, L.; Zhang, R.; Sang, X.; Chan, C.-y.; Lin, Z.; Cao, J. Characteristics and applications of size-segregated biomass burning tracers in China's Pearl River Delta region. Atmos. Environ. 2015, 102, 290-301.

(35) Wang, G.; Kawamura, K.; Umemoto, N.; Xie, M.; Hu, S.; Wang, Z. Water-soluble organic compounds in PM2.5 and sizesegregated aerosols over Mount Tai in North China Plain. J. Geophys. Res. 2009, 114 (D19) DOI: 10.1029/2008JD011390.

(36) Liu, J.; Ding, P.; Zong, Z.; Li, J.; Tian, C.; Chen, W.; Chang, M.; Salazar, G.; Shen, C.; Cheng, Z. Evidence of rural and suburban sources of urban haze formation in China: A case study from the Pearl River Delta region. Journal of Geophysical Research: Atmospheres 2018, 123 (9), 4712-4726.

(37) Lipsky, E. M.; Robinson, A. L. Effects of dilution on fine particle mass and partitioning of semivolatile organics in diesel exhaust and wood smoke. Environ. Sci. Technol. 2006, 40 (1), 155162.

(38) Tuduri, L.; Harner, T.; Hung, H. Polyurethane foam (PUF) disks passive air samplers: Wind effect on sampling rates. Environ. Pollut. 2006, 144 (2), 377-383.

(39) Liu, X.; Zhang, G.; Li, J.; Cheng, H.-R.; Qi, S.-H.; Li, X.-D.; Jones, K. C. Polycyclic aromatic hydrocarbons (PAHs) in the air of Chinese cities. J. Environ. Monit. 2007, 9 (10), 1092-1098.

(40) Shoeib, M.; Harner, T. Characterization and comparison of three passive air samplers for persistent organic pollutants. Environ. Sci. Technol. 2002, 36 (19), 4142-4151.

(41) Wang, Y.; Li, Q. L.; Xu, Y.; Luo, C. L.; Liu, X.; Li, J.; Zhang, G. Improved correction method for using passive air samplers to assess the distribution of PCNs in the Dongiiang River basin of the Pearl River Delta, South China. Atmos. Environ. 2012, 54, 700-705.

(42) Carlton, A. G.; Turpin, B. J. Particle partitioning potential of organic compounds is highest in the Eastern US and driven by anthropogenic water. Atmos. Chem. Phys. 2013, 13 (20), 1020310214 .

(43) Qiao, T.; Zhao, M.; Xiu, G.; Yu, J. Seasonal variations of water soluble composition (WSOC, Hulis and WSIIs) in PM1 and its implications on haze pollution in urban Shanghai, China. Atmos. Environ. 2015, 123, 306-314.

(44) Eng, A.; Su, K.; Harner, T.; Pozo, K.; Sinha, R. K.; Sengupta, B.; Loewen, M. Assessing Dicofol Concentrations in Air: Retrospective Analysis of Global Atmospheric Passive Sampling Network Samples from Agricultural Sites in India. Environ. Sci. Technol. Lett. 2016, 3 (4), 150-155.

(45) Xie, M.; Hannigan, M. P.; Barsanti, K. C. Impact of gas/particle partitioning of semivolatile organic compounds on source apportionment with positive matrix factorization. Environ. Sci. Technol. 2014, 48 (16), 9053-60.

(46) Jariyasopit, N.; Liu, Y.; Liggio, J.; Harner, T. Stability of polycyclic aromatic compounds in polyurethane foam-type passive air samplers upon O 3 exposure. Atmos. Environ. 2015, 120, 200-204.

(47) Hennigan, C. J.; Sullivan, A. P.; Collett, J. L.; Robinson, A. L. Levoglucosan stability in biomass burning particles exposed to hydroxyl radicals. Geophys. Res. Lett. 2010, 37 (9) DOI: 10.1029/ 2010GL043088.

(48) Lai, C.; Liu, Y.; Ma, J.; Ma, Q.; He, H. Degradation kinetics of levoglucosan initiated by hydroxyl radical under different environmental conditions. Atmos. Environ. 2014, 91, 32-39.

(49) Huang, R.-J.; Zhang, Y.; Bozzetti, C.; Ho, K.-F.; Cao, J.-J.; Han, Y.; Daellenbach, K. R.; Slowik, J. G.; Platt, S. M.; Canonaco, F. High secondary aerosol contribution to particulate pollution during haze events in China. Nature 2014, 514 (7521), 218.

(50) Zhang, X.; Tsurukawa, M.; Nakano, T.; Lei, Y. D.; Wania, F. Sampling medium side resistance to uptake of semivolatile organic compounds in passive air samplers. Environ. Sci. Technol. 2011, 45 (24), 10509-10515.

(51) Jariyasopit, N.; Zimmermann, K.; Schrlau, J.; Arey, J.; Atkinson, R.; Yu, T.-W.; Dashwood, R. H.; Tao, S.; Simonich, S. L. M.
Heterogeneous reactions of particulate matter-bound PAHs and $\mathrm{NPAHs}$ with $\mathrm{NO} 3 / \mathrm{N} 2 \mathrm{O} 5, \mathrm{OH}$ radicals, and $\mathrm{O} 3$ under simulated long-range atmospheric transport conditions: Reactivity and mutagenicity. Environ. Sci. Technol. 2014, 48 (17), 10155-10164.

(52) Bohlin, P.; Audy, O.; Škrdlíková, L.; Kukučka, P.; Vojta, Š.; Přibylová, P.; Prokeš, R.; Cupr, P.; Klánová, J. Evaluation and guidelines for using polyurethane foam (PUF) passive air samplers in double-dome chambers to assess semi-volatile organic compounds (SVOCs) in non-industrial indoor environments. Environmental Science: Processes \& Impacts 2014, 16 (11), 2617-2626.

(53) Yang, H.; Yan, R.; Chen, H.; Lee, D. H.; Zheng, C. Characteristics of hemicellulose, cellulose and lignin pyrolysis. Fuel 2007, 86 (12), 1781-1788.

(54) Klánová, J.; Kohoutek, J.; Hamplová, L.; Urbanová, P.; Holoubek, I. Passive air sampler as a tool for long-term air pollution monitoring: Part 1. Performance assessment for seasonal and spatial variations. Environ. Pollut. 2006, 144 (2), 393-405.

(55) Heo, J.; Lee, G. Field-measured uptake rates of PCDDs/Fs and dl-PCBs using PUF-disk passive air samplers in Gyeonggi-do, South Korea. Sci. Total Environ. 2014, 491-492, 42-50.

(56) Mari, M.; Schuhmacher, M.; Feliubadaló, J.; Domingo, J. L. Air concentrations of $\mathrm{PCDD} / \mathrm{Fs}, \mathrm{PCBs}$ and $\mathrm{PCNs}$ using active and passive air samplers. Chemosphere 2008, 70 (9), 1637-1643.

(57) Herkert, N. J.; Spak, S. N.; Smith, A.; Schuster, J. K.; Harner, T.; Martinez, A.; Hornbuckle, K. C. Calibration and evaluation of PUF-PAS sampling rates across the Global Atmospheric Passive Sampling (GAPS) network. Environmental Science: Processes \& Impacts 2018, 20 (1), 210-219.

(58) Chaemfa, C.; Wild, E.; Davison, B.; Barber, J. L.; Jones, K. C. A study of aerosol entrapment and the influence of wind speed, chamber design and foam density on polyurethane foam passive air samplers used for persistent organic pollutants. J. Environ. Monit. 2009, 11 (6), $1135-1139$.

(59) Zhang, Z.; Engling, G.; Lin, C.-Y.; Chou, C. C. K.; Lung, S.-C. C.; Chang, S.-Y.; Fan, S.; Chan, C.-Y.; Zhang, Y.-H. Chemical speciation, transport and contribution of biomass burning smoke to ambient aerosol in Guangzhou, a mega city of China. Atmos. Environ. 2010, 44 (26), 3187-3195.

(60) Ho, K. F.; Engling, G.; Ho, S. S. H.; Huang, R. J.; Lai, S. C.; Cao, J. J.; Lee, S. C. Seasonal variations of anhydrosugars in PM2.5 in the Pearl River Delta Region, China. Tellus, Ser. B 2014, 66 (1), 22577.

(61) Ding, X.; Wang, X. M.; Gao, B.; Fu, X. X.; He, Q. F.; Zhao, X. Y.; Yu, J. Z.; Zheng, M. Tracer-based estimation of secondary organic carbon in the Pearl River Delta, south China. J. Geophys. Res.: Atmos. 2012, 117 (D5) DOI: 10.1029/2011JD016596.

(62) Fu, P. Q.; Kawamura, K.; Okuzawa, K.; Aggarwal, S. G.; Wang, G. H.; Kanaya, Y.; Wang, Z. F. Organic molecular compositions and temporal variations of summertime mountain aerosols over Mt. Tai, North China Plain. J. Geophys. Res.: Atmos2008, 113 (D19) DOI: $10.1029 / 2008$ JD009900.

(63) Sheesley, R. J.; Schauer, J. J.; Chowdhury, Z.; Cass, G. R.; Simoneit, B. R. T. Characterization of organic aerosols emitted from the combustion of biomass indigenous to South Asia. J. Geophys. Res.-Atmos. 2003, 108 (D9) DOI: 10.1029/2002JD002981.

(64) Zhang, T.; Claeys, M.; Cachier, H.; Dong, S.; Wang, W.; Maenhaut, W.; Liu, X. Identification and estimation of the biomass burning contribution to Beijing aerosol using levoglucosan as a molecular marker. Atmos. Environ. 2008, 42 (29), 7013-7021.

(65) Zhu, C.; Kawamura, K.; Kunwar, B. Effect of biomass burning over the western North Pacific Rim: wintertime maxima of anhydrosugars in ambient aerosols from Okinawa. Atmos. Chem. Phys. 2015, 15 (4), 1959-1973.

(66) Puxbaum, H.; Caseiro, A.; Sanchez-Ochoa, A.; Kasper-Giebl, A.; Claeys, M.; Gelencser, A.; Legrand, M.; Preunkert, S.; Pio, C. Levoglucosan levels at background sites in Europe for assessing the impact of biomass combustion on the European aerosol background. J. Geophys. Res. 2007, 112 (D23) DOI: 10.1029/2006JD008114. 
(67) Chan, C.-Y.; Engling, G.; Sang, X.; Zhang, T. Biofuel Combustion Emissions-Chemical and Physical Smoke Properties; Environmental Impact of Biofuels, InTech: 2011.

(68) van Drooge, B. L.; Fontal, M.; Bravo, N.; Fernandez, P.; Fernandez, M. A.; Munoz-Arnanz, J.; Jimenez, B.; Grimalt, J. O. Seasonal and spatial variation of organic tracers for biomass burning in PM1 aerosols from highly insolated urban areas. Environ. Sci. Pollut. Res. 2014, 21 (20), 11661-70.

(69) Lu, A. F.; Tian, H. Q.; Liu, M. L.; Liu, J. Y.; Melillo, J. M. Spatial and temporal patterns of carbon emissions from forest fires in China from 1950 to 2000. J. Geophys. Res. 2006, 111 (D5) DOI: $10.1029 / 2005 J D 006198$.

(70) Song, Y.; Liu, B.; Miao, W.; Chang, D.; Zhang, Y. Spatiotemporal variation in nonagricultural open fire emissions in China from 2000 to 2007. Global Biogeochem. Cycles 2009, 23, 23.

(71) Gustafsson, O.; Krusa, M.; Zencak, Z.; Sheesley, R. J.; Granat, L.; Engstrom, E.; Praveen, P. S.; Rao, P. S. P.; Leck, C.; Rodhe, H. Brown Clouds over South Asia: Biomass or Fossil Fuel Combustion? Science 2009, 323 (5913), 495-498. 